\title{
Studying Away and Well-Being: A Comparison Study Between International and Home Students in the UK
}

\author{
Eman S. Alharbi ${ }^{1}$ \& Andrew P. Smith ${ }^{1}$ \\ ${ }^{1}$ Centre for Occupational and Health Psychology, School of Psychology, Cardiff University, United Kingdom \\ Correspondence: Eman S. Alharbi, Centre for Occupational and Health Psychology, School of Psychology, Cardiff \\ University, 63 Park Place, Cardiff, CF10 3AS, United Kingdom.
}

Received: September 30, 2018

Accepted: November 12, 2018

Online Published: May 29, 2019

doi:10.5539/ies.v12n6p1

URL: https://doi.org/10.5539/ies.v12n6p1

\begin{abstract}
The aim of this study was to investigate the impact of being away from home on the well-being of international and domestic UK university students as a function of demographic factors, course load, support, personality, healthy lifestyle, and their employment of pre-planning and being at university strategies. A total of 510 students $(\mathrm{n}=391$ international and 117 British) completed an on-line survey to record demographic details and measure their well-being, quality of university life, and their being away from home strategies. The findings showed that International students reported greater quality of university life and used more pre-departure strategies; the female students reported a significantly more negative well-being and higher course demand than their male peers. A regression analysis showed that positive well-being was predicted by a positive personality, a healthy lifestyle, control and support for academic work, quality of university life and employing well-being strategies (using technology without over-reliance on it and the ability to unwind from study). Negative well-being, on the other hand, was predicted by a less positive personality and a less healthy lifestyle, a higher course demand, less control and support for academic work and less quality of university life. Moreover, the regression analysis showed that international students who employed more pre-departure strategies showed less negative well-being.
\end{abstract}

Keywords: well-being, well-being away, studying away strategies, international students, home students, studying abroad and quality of university life

\section{Introduction}

Studying at university has the potential to provide a positive experience to students by offering them a significant opportunity to meet and connect with new people and ideas, start their adult life, and make a better future for themselves through earning higher education qualifications. Nevertheless, students in universities are likely to face adjustment challenges which may manifest as mental health issues with varying degrees of impact (Rahat \& Ilhan, 2016). In addition to academic challenges and financial issues, it is also common for students in higher education to leave home for their studies, which can have a significant impact on individual well-being especially for international students in new cultural environments (Mortenson, 2006; Sandhu \& Asrabadi, 1994).

Indeed, previous studies reported an association between moving from home for study or work and negative mental health outcomes, such as depression and homesickness (e.g., Andrade, 2006; Chen, 1999). It has also been reported that different populations of work and study sojourners experience negative physical health impacts as a result of being away from home such as fly-in fly-out (FIFO) workers (Gardner, Vandelanotte, \& Rebar, 2018), immigrants (Gilliver, Sundquist, \& Sundquist, 2014), boarding school pupils (Fisher, Frazer, \& Murray, 1984) and international students (Andrade, 2006; Chen, 1999; Mori, 2000). All these negative psychological and physical outcomes have been related to the away from home transition when an individual cannot adapt to the new environment, cope with difficulties and challenges, and lose contact with significant social support networks.

Despite some important research on the psychological effects of studying away from home amongst university students, few studies have investigated the full range of elements that may impact on the well-being of study away from home students. A recent review of the literature on international students' well-being (Alharbi \& Smith, 2018) showed that a limited amount of research has investigated all aspects of their well-being, with most studies neglecting students' expectations, pre-arrival planning, as well as the effects of university courses and environment on students' well-being. Therefore, to address this gap, this study will apply Sodexo's (2014) model 
of well-being away, which will be discussed in more detail later in this paper.

A complete model of mental health requires not just the absence of psychopathology, but also a focus on positive indices of functioning such as subjective well-being (Keyes, 2005). Well-being can further be delineated as the presence of positive affect, the lack of negative affect and a high degree of life satisfaction. Moreover, well-being is also affected by different demographic and social factors such as age, gender, ethnicity, income, social support networks and personality. The aim of this study was to investigate the impact of being away from home amongst university students in terms of their well-being and as a function of demographic and social factors. A further aim is to investigate if the relationship between studying away from home and well-being differs between university students from abroad and local students who may likewise leave home for study but within their own country.

\subsection{Being Away from Home and Well-Being among University Students}

In recent years, a significant proportion of university students have left home to pursue their studies as an international or domestic student (UKCISA, 2016-17). Whether studying internationally or within their own country, students who leave home for their higher education often feel negative effects from being in a new environment and because their home plays a central role in everyday life and holds numerous psychological meanings (Moore, 2000). For example, a range of studies have found that international students in particular are at a higher risk of developing psychological problems due to increased stress from being away from home (e.g., Mortenson, 2006; Sandhu \& Asrabadi, 1994).

In one study, Fisher and Hood (1987) conducted a longitudinal investigation of the negative effects of leaving home for study. The study included two measurement phases (two months before the semester began and six weeks after) that examined and compared the level of psychological disturbance and homesickness experienced by first-year university residents and home-based students; most of them were university residents and only two were home-based students. The findings showed all students showed higher scores on depression, obsessionality and anxiety after transitioning to university. In addition, students who reported homesickness reported a higher level of psychological disturbance, especially depression and somatic symptoms. Furthermore, students with anxiety and somatic symptoms were more sensitive to the transition than those with depression.

Adapting to a university environment plays an important role in succeeding in university; however, failure to adjust to new environments is more often a cause for dropout or underperformance (Pitkethly \& Prosser, 2001). Furthermore, difficulties in adapting to the host environment leads to acculturative stress among international students, which is often associated with anxiety and depression (Constantine, Okazaki, \& Utsey, 2004). International students have a greater difficulty adjusting to university life than domestic students and the process may take a longer time due to the fact students expend effort to adapt to other fundamental aspects of university life, such as the academic system, and more general factors such as changes in climate and diet (Hechanova-Alampay, Beehr, Christiansen, \& Van Horn, 2002).

Although there has been important research on the psychological effects of leaving home to study, there has been little focus on the well-being of university students; most research has focussed on emotional effects of away from home study, such as happiness or stress. Importantly, factors such as the university environment, learning processes, course demands, and the support of university campuses and services are likely to impact on the well-being of away from home students, but are rarely included in the existing research literature on student wellbeing. Indeed, the available literature tends to compare domestic and international students on outcomes of being away from home such as stress, financial satisfaction, psychological distress, coping strategies, academic stress and adjustment (e.g., Hamamura \& Laird, 2014; Khawaja \& Dempsey, 2008; Sanders \& Lushington 1999). Moreover, research has tended to focus on the process of transition or daily hassles like academic difficulties experienced by student sojourners rather than conceptualising the adjustment process as one that entails several stages that impact on well-being.

\subsection{Well-Being Away Strategies and Quality of University Life}

The process of adjustment to a new social context has been the subject of research on acculturation for some time (e.g., Kealy, 1989; Ward \& Kennedy, 2001) and has also been adapted to the experience of students who leave home to pursue higher education (e.g., Martin, Bradford, \& Rohrlich, 1995; Simmala, 2008). In one recent model, the Sodexo Institute (Sodexo, 2014; A. Smith, H. Smith, \& Jelley, 2018) proposes a five-stage model of well-being away so individuals and organisations can "better understand the experience of being away and increase the chances of maintaining psychological wellbeing" (p. 1). This model suggests a few strategies at each stage of the transition that help an individual to maintain and manage their own level of well-being, make the adapting process much easier and with fewer negative outcomes. 
The Sodexo model (2014; A. Smith, H. Smith, \& Jelley, 2018) proposes five phases of transition commencing with Pre-departure planning, which includes developing expectations about being away, acknowledging that the coming separation is real, setting up a support network and, more importantly, planning for contacting and communicating with family at home. The Sodexo researchers raise the idea that with current technology people tend to think that technology will mitigate the separation. Nevertheless, that is not necessarily the case when the person is away and working long hours with little free time. The second phase of the Sodexo model (2014) is labelled Being away and includes two main factors. The first factor includes using technology without over-reliance on it. The second involves developing the ability to unwind from work or study, as it is known that dwelling on work- or study-related issues lead to negative effects and other health-related problems. The model also emphasises changing activities and doing something different from studying. For example, it is better for a student to exercise in their free time rather than doing something similar to what they usually do such as surfing the internet. The third phase of the model is Preparing to return which is theorised to have a real impact on well-being. One important thing to realise is that people (both the person who is away from home and their family or friends) change, even over short periods of time and that has an impact at the level of wellbeing. One factor that could help at this stage is to change activities before returning home. The fourth phase entails Returning, which is the last stage of being away where increasing the amount of leisure or relaxation time is important. The final stage is Being back wherein a student is back at home and needs to readjust to their home country. In theory, disconnections between being back and feeling psychologically back affect the level of wellbeing. Despite the plausibility of the Sodexo (2014) well-being away model, there has been little investigation of its applicability in real life cases where students or sojourners move from home to pursue study and work. A central aim of this study was to investigate how this model may explain the quality of university life and well-being experiences of students who venture from home to complete higher education studies.

The concept of quality college and university life has been examined in many studies as an important factor that affects student academic success, loyalty, and university recommendation. University managers and administrators aim to maximise the quality of university life (QUL) because studying at university can be challenging and QUL has an impact on the university's ranking. Sirgy et al. (2007) refer to the quality of college life (QCL) as the "overall feeling of satisfaction student's experiences in college". They include three domains of QCL satisfaction, related to academic, social, and university facilities and services, which are all included in this study.

A. Smith, H. Smith and Jelley (2018) conducted a preliminary study to examine associations between studying away strategies, quality of student life and well-being of international students in the UK. The results showed that more frequent use of studying away strategies increased quality of university life. Quality of university life was one of the predictors of well-being and the results from this study suggested that studying away strategies influence well-being by improving quality of university life. Smith et al (2018) consider the full model of studying away strategies while this study focused only on two stages.

\section{The Current Study}

The current study was designed to investigate the impact of being away from home amongst university students with three central aims. First, the study investigated student well-being in terms of positive and negative aspects and as a function of course loads, supports, quality of university life, personality, healthy lifestyle and a range of demographic and social factors. A second aim was to investigate if the relationship between studying away from home and well-being differs between university students from abroad and local students who may likewise leave home for study but within their own country. A third and final aim was to investigate the efficacy of the five-stage well-being away model in terms of the pre-departure and being in university strategies employed by study away from home students. Altogether, the study addressed a number of research questions based on a review of the research literature:

RQ1: To what extent do university students away from home experience positive and negative well-being as a function of their course load, support, personality, and healthy lifestyle?

RQ2: To what extent do international and UK students studying away from home differ in their level of positive and negative well-being?

RQ3: To what extent does the use of pre-departure and being in university strategies predict quality of university life and positive and negative well-being of UK university students studying away from home? 


\section{Methods}

\subsection{Procedure and Participants}

Approval for this study was obtained from the ethics committee of the school of Psychology, Cardiff University. British participants were recruited from psychology courses, and international students were recruited from different schools and universities in both England and Wales. Participants completed the questionnaire online using Qualtrics software. All participants volunteered for the study and the survey took approximately 10-15 minutes to complete.

A total of 510 students participated in this study, of which $23 \%$ were British students who were studying away from home, and $77 \%$ were international students from a variety of other countries. The students' ages ranged from $16-50$ years $(M=21.90$ years, $S D=3.13)(48.8 \%=$ males, $51.2 \%=$ females $)$. Of all the participants, 265 $(52 \%)$ were in their first year at university. Regarding race, the majority of the British sample was white (85.5\%), followed by Asian (7.7\%), mixed race (4.3\%) and Black or African (2.6\%). For international students, the majority were white (47.6\%), followed by Asian (25.3\%), Black or African (14.1\%), Hispanic/Latino (8.7\%), Arab $(2.3 \%)$ and mixed race $(2.0 \%)$. Table 1 provides a summary of the participants' demographic details.

Table 1. Demographic characteristics of participants

\begin{tabular}{lcc}
\hline Demographics & $\begin{array}{c}\text { British students } \\
(n=117)\end{array}$ & $\begin{array}{c}\text { International students } \\
(n=391)\end{array}$ \\
\hline $\begin{array}{l}\text { Mean Age }(S D) \\
\text { Gender }\end{array}$ & $20.61(2.23)$ & $22.28(3.26)$ \\
Male & 57 & 191 \\
Female & 60 & 200 \\
Class status & & \\
First year & 46 & 218 \\
Other year & 71 & 173 \\
\hline
\end{tabular}

\subsection{Measures}

The study employed a self-report questionnaire that included the following questions and scales:

1) Demographic Questionnaire, including gender, age, university year and nationality.

2) Smith Student Well-being Questionnaire (SWELL). The 18 self-report items covered a range of aspects of well-being, including course demands, control over and support with studying, positive/negative mental health, positive personality and healthy lifestyle.

3) Quality of University Life Questionnaire. The 6-item scale measured different elements that relate to the quality of university life, including the university environment and learning (e.g. 'To what extent do you feel that your university life is easy and efficient?'), which were rated on a 10-point Likert scale, ranging from $1=$ Not at all to $10=$ Very much .

4) Being Away Strategies Questionnaire. The 7-item scale measured different strategies in each stage of the transition to being away from home (e.g. 'To what extent did you carry out pre-departure planning with family and friends?'), which were rated on a 10-point Likert scale, ranging from $1=$ Not at all to $10=$ Very much. In this study, the focus was on two transition stages: pre-departure planning and being away. All measures used appear in the appendix.

\section{Results}

\subsection{Analysis Strategy}

Statistical analyses were performed using Statistical Package for Social Sciences (SPSS) Version 23. Chi-square $\left(\chi^{2}\right)$ and t-test statistical analyses were conducted to investigate potential differences between International and British students on age and gender. A multivariate analysis of covariance was conducted to investigate significant mean differences between international and home students, male and female students as well as first year and non-first year students. Finally, a series of hierarchical regressions was conducted to determine if demographic variables, course demand, control and support, quality of university life, pre-departure and being away from home university strategies predict positive and negative well-being and positive and negative university life. 


\subsection{Reliability of Scales}

The responses of the entire sample were used to determine the internal consistencies of the measures. The Cronbach's alpha coefficient for the well-being questionnaire was $\alpha=.76$, the quality of university life questionnaire was $\alpha=.77$ and the being away strategies questionnaire was $\alpha=.72$, all of which indicated an acceptable level of reliability.

\subsection{Analyses of Demographics}

Chi-square tests were conducted to examine the differences between international and British students regarding gender and year at university, and an independent sample t-test was conducted to examine the difference between both groups regarding age. The chi-square analyses indicated no significant differences between the International and British students on demographics: gender $\chi^{2}(1, N=510)=0.28, p=.59$; year at university $\chi^{2}(1, N=510)=$ $0.784, p=.376$. The independent samples t-test showed a significant difference between the groups on age, with British students being significantly younger than international students, $t(505)=5.21, p<.05$, Cohen's $\mathrm{d}=0.6$. Thus, age was controlled as a co-variate when comparing the two groups.

\subsection{Comparisons of Well-Being, Adjustment Strategies and Quality of University Life}

A MANCOVA was employed to investigate whether there were differences between international and home students, first and non-first year students, as well as male and female students in terms of the study variables. Prior to conducting the test, several analyses were performed between all the dependent variables in order to test the MANCOVA assumptions. The correlation between the 11 dependant variables ranged from .022 to +.523 , indicating the absence of multicollinearity but and Levene's test showed violation in some of the dependant variables and the Box's $M$ test did indicate a violation of the assumption of homogeneity as a result Pillai's trace will be reported instead of Willks's Lambda as it more robust to violation of the homogeneity of variance and preferred for unequal sample sizes and the alpha level were reduced to .01 to address the violation of homogeneity of error variances assumptions. Using Pillai's trace show a significant effect of nationality, $F(10$, 464) 3.91, $p<.001$, partial $\eta^{2}=.078$, gender, $F(10,464) 3.09, p<.001$, partial $\eta^{2}=.063$. and year at university $F$ $(10,464) 5.71, p<.001$ partial $\eta^{2}=.110$. The covariate variable (age) also yielded a significant result $F(10,464)$ $=2.15, p=.006$ partial $\eta^{2}=.051$. No significant interaction effects were found.

The results reported in Table 2 show significant differences were found between international and British students for positive personality, course demand, quality of university life, pre-departure strategies and negative wellbeing. International students had significantly higher scores than the British students for all the mentioned variables except negative well-being and course demand.

Table 2. F-tests comparing international and home students

\begin{tabular}{|c|c|c|c|c|c|c|}
\hline \multirow{2}{*}{ Dependent Variables } & \multicolumn{2}{|c|}{ British } & \multicolumn{2}{|c|}{ International } & \multirow{2}{*}{$F$} & \multirow{2}{*}{ Partial eta-square } \\
\hline & $M$ & $S D$ & $M$ & $S D$ & & \\
\hline Healthy lifestyle & 6.56 & 1.70 & 6.61 & 1.99 & .710 & .001 \\
\hline Positive personality & 6.17 & 1.83 & 6.74 & 1.72 & $9.69 *$ & .020 \\
\hline Course demand & 7.03 & 1.61 & 6.62 & 1.65 & $6.40^{*}$ & .013 \\
\hline Control and support & 6.18 & 1.77 & 6.53 & 1.94 & .370 & .001 \\
\hline Quality of university life & 34.76 & 8.81 & 38.59 & 8.00 & $13.14^{*}$ & .027 \\
\hline Pre-departure strategies & 22.87 & 7.39 & 26.21 & 6.6 & $13.10^{*}$ & .027 \\
\hline Being away strategies & 20.13 & 3.89 & 20.04 & 3.96 & .095 & .000 \\
\hline Positive well-being & 13.04 & 3.68 & 13.63 & 3.07 & 1.93 & .004 \\
\hline Negative well-being & 12.50 & 3.83 & 11.47 & 3.24 & $9.33^{*}$ & .019 \\
\hline Illness and presenteeism & 9.69 & 1.72 & 9.53 & 1.84 & .802 & .002 \\
\hline
\end{tabular}

Note. ${ }^{*} p<0.01$.

Table 3 shows significant differences were found between male and female students for positive personality, course demand, negative well-being and illness, with female students reporting significantly higher than male students for all the mentioned variables except positive personality. 
Table 3. F-tests comparing male and female students

\begin{tabular}{llcccccc}
\cline { 2 - 5 } Dependent Variables & \multicolumn{3}{c}{ Male } & \multicolumn{3}{c}{ Female } & \multirow{2}{*}{ Partial eta-square } \\
\cline { 2 - 6 } & $M$ & $S D$ & $M$ & $S D$ & & .002 \\
\cline { 2 - 6 } Healthy lifestyle & 6.56 & 2.01 & 6.64 & 1.85 & .799 & .021 \\
Positive personality & 6.88 & 1.75 & 6.35 & 1.73 & $10.31^{*}$ & .021 \\
Course demand & 6.45 & 1.59 & 6.98 & 1.66 & $10.12^{*}$ & .001 \\
Control and support & 6.54 & 1.81 & 6.33 & 2.00 & .528 & .004 \\
Quality of university life & 38.74 & 8.78 & 36.71 & 7.80 & 1.73 & .001 \\
Pre-departure strategies & 25.48 & 7.10 & 25.14 & 6.77 & .582 & .000 \\
Being away strategies & 19.97 & 3.81 & 20.19 & 4.07 & .000 & .008 \\
positive well-being & 13.76 & 3.31 & 12.76 & 3.08 & 3.91 & .028 \\
Negative well-being & 11.04 & 3.49 & 12.32 & 3.22 & $13.5^{*}$ & .015 \\
\hline Illness and presenteeism & 9.38 & 1.89 & 9.74 & 1.72 & $7.19^{*}$ & & \\
\hline
\end{tabular}

Note. ${ }^{*} p<0.01$.

There were also significant differences between first and non-first year students for healthy lifestyle, quality of university life, control and over academic work and pre-departure strategies. First year students reported higher scores than non-first students for all the mentioned variables (see Table 4).

Table 4. F-tests comparing first year and non-first year students

\begin{tabular}{lcccccc}
\hline \multirow{2}{*}{ Dependent Variables } & \multicolumn{7}{c}{ First year } & \multicolumn{3}{c}{ Non-first year } & \multirow{2}{*}{$F$} & \multirow{2}{*}{ Partial eta-square } \\
\cline { 2 - 6 } & $M$ & $S D$ & $M$ & $S D$ & & .033 \\
\cline { 2 - 6 } Healthy lifestyle & 7.06 & 1.94 & 5.83 & 1.78 & $16.22^{*}$ & .002 \\
Positive personality & 6.85 & 1.80 & 6.36 & 1.68 & .877 & .000 \\
Course demand & 6.70 & 1.52 & 6.75 & 1.77 & .178 & .017 \\
Control and support & 6.75 & 1.80 & 6.10 & 1.97 & $8.05^{*}$ & .073 \\
Quality of university life & 40.53 & 8.37 & 34.69 & 7.20 & $37.45^{*}$ & .056 \\
Pre-departure strategies & 27.23 & 6.56 & 23.26 & 6.73 & $28.04^{*}$ & .006 \\
Being away strategies & 20.60 & 3.79 & 19.41 & 3.82 & 2.97 & .011 \\
Positive well-being & 14.11 & 3.23 & 12.76 & 3.08 & 5.09 & .002 \\
Negative well-being & 11.31 & 3.64 & 12.10 & 3.10 & .960 & .010 \\
Illness and presenteeism & 9.32 & 1.68 & 9.84 & 1.90 & 4.69 & \\
\hline
\end{tabular}

Note. ${ }^{*} p<0.01$.

\subsection{Regression Analysis}

Four 3-step hierarchical multiple regressions were conducted to investigate the relationships between the predictors and the outcomes of positive well-being, negative well-being, quality of university life and illness and presentism. Healthy lifestyle, positive personality, age, gender, nationality and year at university were entered as predictors in Step 1 of the regression while course demand, control and support, QUL, pre-departure strategies and being away at university strategies were entered as predictors in Step 2 of the regression. The interaction between nationality and course demand, support, QUL, pre-departure strategies and being away strategies were entered at Step 3 of the regression. To do so, Nationality was dummy coded as 0 for British students and 1 for International students.

The first regression was conducted to determine the predictors of positive well-being with the full results shown in Table 5. The variables entered at Step 1 significantly predicted positive well-being, $F(6,509)=53.80, p$ $<.001$ and explained $38 \%$ of the variance in positive well-being. The regression coefficients showed students with a healthy lifestyle and a positive personality reported higher positive well-being, whereas first year students showed higher positive well-being than other students. At Step 2 of the regression, the model was also significant, $F(11,509)=43.5, p<.001$, and explained $47.9 \%$ of the variance in positive well-being. The regression coefficients showed three additional variables were significant predictors of positive well-being such that students with higher control and support, QUL and being away strategies reported higher positive well-being. However, these three variables did not predict positive well-being at Step 3 of the regression. Instead, the interaction between nationality and course demands was a significant predictor of positive 
well-being such that international students with less course demands reported higher positive well-being. Overall, the full model was significant, $F(16,509)=30.65, p<.001$, and explained $50 \%$ of the variance in positive well-being.

Table 5. Standardised regression coefficients $(\beta)$ of predictors of positive well-being

\begin{tabular}{|c|c|c|c|}
\hline Variables & Step 1 & Step 2 & Step 3 \\
\hline Age & .05 & .03 & .03 \\
\hline Gender & -.03 & -.02 & -.02 \\
\hline Nationality & -.01 & -.03 & .25 \\
\hline Year at university & -.07 & .007 & -.006 \\
\hline Healthy lifestyle & $.30 * * *$ & $.18^{* * *}$ & $.17 * * *$ \\
\hline Positive personality & $.44 * * *$ & $.35^{* * *}$ & $.35 * * *$ \\
\hline Course demand & & .02 & $.26^{* *}$ \\
\hline Control and support & & $.16^{* * *}$ & .16 \\
\hline Quality of university life & & $.21 * * *$ & .17 \\
\hline Pre-departure strategies & & -.009 & .16 \\
\hline Being away strategies & & $.13 * * *$ & .20 \\
\hline Nationality $\times$ Course demand & & & $-.47 * *$ \\
\hline Nationality $\times$ Support & & & -.12 \\
\hline Nationality $\times$ Quality of university life & & & .045 \\
\hline Nationality $\times$ Pre-departure strategies & & & .24 \\
\hline Nationality $\times$ Being away strategies & & & -.041 \\
\hline Step $1 R^{2}$ & .39 & & \\
\hline Step $1 F$ & $53.80 * * *$ & & \\
\hline Step $2 R^{2}$ & & .49 & \\
\hline Step $2 F$ & & $43.5 * * *$ & \\
\hline Step $3 R^{2}$ & & & .50 \\
\hline Step3 $F$ & & & $30.65^{* * *}$ \\
\hline Adjusted $R^{2}$ & .38 & .47 & .48 \\
\hline
\end{tabular}

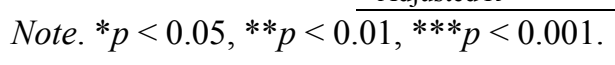

The next regression was conducted to determine the predictors of negative well-being with the full results shown in Table 6. The variables entered at Step 1 significantly predicted negative well-being, $F(6,509)=18.79, p$ $<.001$ and explained $18.2 \%$ of the variance in negative well-being. The regression coefficients showed older and female students reported higher negative well-being as did British students compared to international students. Moreover, students with a less healthy lifestyle and less positive personality showed higher negative well-being. At Step 2 of the regression, the model was also significant, $F(11,509)=14.93, p<.001$, and explained $24.8 \%$ of the variance in negative well-being. The regression coefficients showed three additional variables were significant predictors of negative well-being such that students with higher course demand, lower control and support, and lower quality of university life reported higher negative well-being. The findings were further qualified by a significant interaction between nationality and pre-departure strategies at Step 3 of the regression. Regression coefficients showed that International students who employed more pre-departure strategies showed lower negative well-being. Overall, the full model was significant, $F(16,509)=11.24, p<.001$, and explained $27 \%$ of the variance in negative well-being. 
Table 6. Standardised regression coefficients $(\beta)$ of predictors of negative well-being

\begin{tabular}{|c|c|c|c|}
\hline Variables & Step 1 & Step 2 & Step 3 \\
\hline Age & $.10^{*}$ & $.08 *$ & $.09 *$ \\
\hline Gender & $.15 * *$ & $.10^{*}$ & $.08^{*}$ \\
\hline Nationality & $-.10^{*}$ & -.06 & .20 \\
\hline Year at university & .002 & -.04 & -.05 \\
\hline Healthy lifestyle & $-.13 * * *$ & $-.103 *$ & -.092 \\
\hline Positive personality & $-.30 * * *$ & $-.27 * * *$ & $-.25 * * *$ \\
\hline Course demand & & $.16^{* * *}$ & .305 \\
\hline Control and support & & $-.14 * *$ & -.179 \\
\hline Quality of university life & & $-.142 *$ & $-.369^{* *}$ \\
\hline Pre-departure strategies & & -.004 & .497 \\
\hline Being away strategies & & $.097^{*}$ & .062 \\
\hline Nationality $\times$ Course demand & & & -.20 \\
\hline Nationality $\times$ Support & & & -.067 \\
\hline Nationality $\times$ Quality of university life & & & .348 \\
\hline Nationality $\times$ Pre-departure strategies & & & $-.74 * * *$ \\
\hline Nationality $\times$ Being away strategies & & & .052 \\
\hline Step $1 R^{2}$ & .18 & & \\
\hline Step $1 F$ & $18.79 * * *$ & & \\
\hline Step $2 R^{2}$ & & .24 & \\
\hline Step $2 F$ & & $14.93 * * *$ & \\
\hline Step $3 R^{2}$ & & & .27 \\
\hline Step3 F & & & $11.24 * * *$ \\
\hline Adjusted $R^{2}$ & .17 & .23 & .25 \\
\hline
\end{tabular}

Note. ${ }^{*} p<0.05, * * p<0.01,{ }^{* * *} p<0.001$.

A third multiple regressions were conducted to determine the predictors of quality of university life (QUL) with the full results shown in Table 7. The variables entered at Step 1 significantly predicted QUL, $F(6,509)=35.38$, $p<.001$ and explained $29.7 \%$ of the variance in QUL. The regression coefficients showed first year students, international students, healthy lifestyle and positive personality showed higher scores on QUL. At Step 2 of the regression, the model was also significant, $F(10,509)=43.18, p<.001$, and explained $46.4 \%$ of the variance in QUL. The regression coefficients showed four additional variables were significant predictors of QUL such that students with lower course demand, higher control and support, employed more pre-departure strategies and being away strategies reported higher QUL. At Step 3 of the regression model, there was a significant effect of nationality on QUL as a function of course demand and support. Overall, the full model was significant, $F(14$, $509)=32.75, p<.001$, and explained $48.1 \%$ of the variance in QUL. 
Table 7. Standardised regression coefficients $(\beta)$ of predictors of quality of university life (QUL)

\begin{tabular}{|c|c|c|c|}
\hline Variables & Step 1 & Step 2 & Step 3 \\
\hline Age & .03 & -.03 & .04 \\
\hline Gender & -.06 & .05 & -.05 \\
\hline Nationality & $.11 * * *$ & -.06 & $.63 * * *$ \\
\hline Year at university & $-.26 * * *$ & $-.18 * * *$ & $-.19 * * *$ \\
\hline Healthy lifestyle & $.21 * * *$ & .05 & .05 \\
\hline Positive personality & $.25 * * *$ & $.15^{* * *}$ & $.13 * * *$ \\
\hline Course demand & & $-.10 * * *$ & .07 \\
\hline Control and support & & $.28 * * *$ & $.43 * * *$ \\
\hline Pre-departure strategies & & $.23 * * *$ & $.24 * * *$ \\
\hline Being away strategies & & $.16^{* * *}$ & .11 \\
\hline Nationality $\times$ Course demand & & & $-.44 * * *$ \\
\hline Nationality $\times$ Support & & & $-.33 *$ \\
\hline Nationality $\times$ Pre-departure strategies & & & -.04 \\
\hline Nationality $\times$ Being away strategies & & & .17 \\
\hline Step $1 R^{2}$ & .29 & & \\
\hline Step $1 F$ & $35.38 * * *$ & & \\
\hline Step $2 R^{2}$ & & .46 & \\
\hline Step $2 F$ & & $43.18 * * *$ & \\
\hline Step $3 R^{2}$ & & & .48 \\
\hline Step3 $F$ & & & $32.75 * * *$ \\
\hline Adjusted $R^{2}$ & .28 & .45 & .47 \\
\hline
\end{tabular}

Note. ${ }^{*} p<0.05, * * p<0.01, * * * p<0.001$.

The final regression was conducted to determine the predictors of illness and presenteeism with the full results shown in Table 8. The variables entered at Step 1 significantly predicted illness and presenteeism, $F(6,509)=$ $4.16, p<.001$ and explained $21.8 \%$ of the variance in illness and presenteeism. The regression coefficients showed being less healthy life style and non-first year students reported higher illness and presenteeism. At Step 2 of the regression, the model was also significant, $F(11,509)=10.05, p<.001$, and explained $42.6 \%$ of the variance in illness and presenteeism. The regression coefficients showed only one additional variable was significant predictor of illness and presenteeism such that students with higher course demand reported higher illness. The findings were further qualified by a significant interaction between nationality and control and support and nationality and QUL at Step 3 of the regression. Regression coefficients showed that British students with a lower QUL reported more illness. Overall, the full model was significant, $F(16,509)=7,792, p<.001$, and explained $50 \%$ of the variance in illness and presenteeism. 
Table 8. Standardised regression coefficients $(\beta)$ of predictors of illness and presenteeism

\begin{tabular}{|c|c|c|c|}
\hline Variables & Step 1 & Step 2 & Step 3 \\
\hline Age & .003 &.-03 & -.03 \\
\hline Gender &. .08 & .02 & .02 \\
\hline Nationality & -.015 & .04 & .27 \\
\hline Year at university & $.09^{*}$ & .07 & .06 \\
\hline Healthy lifestyle & $-.12 * *$ & $-.12 *$ & $-.109^{*}$ \\
\hline Positive personality & -.05 & -.01 & -.05 \\
\hline Course demand & & $.37 * * *$ & $.34 * * *$ \\
\hline Control and support & & -.02 & $-.27 * *$ \\
\hline Quality of university life & & -.08 & .17 \\
\hline Pre-departure strategies & & .03 & -.02 \\
\hline Being away strategies & & -.04 & .03 \\
\hline Nationality $\times$ Course demand & & & .03 \\
\hline Nationality $\times$ Support & & & $.52 * *$ \\
\hline Nationality $\times$ Quality of university life & & & $-.71 * * *$ \\
\hline Nationality $\times$ Pre-departure strategies & & & .13 \\
\hline Nationality $\times$ Being away strategies & & & -.20 \\
\hline Step $1 R^{2}$ & .047 & & \\
\hline Step $1 F$ & $4.16^{* * *}$ & & \\
\hline Step $2 R^{2}$ & & .182 & \\
\hline Step $2 F$ & & $10.05 * * *$ & \\
\hline Step $3 R^{2}$ & & & .202 \\
\hline Step3 F & & & $7.8 * * *$ \\
\hline Adjusted $R^{2}$ & .036 & .146 & .167 \\
\hline
\end{tabular}

\section{Discussion}

Within the context of research on student health and well-being, the current study investigated the well-being of away from home university students in terms of positive and negative aspects and as a function of course load, support, QUL, personality, healthy lifestyle and a range of demographic and social factors. Moreover, the study also investigated if the relationship between studying away from home and well-being differs between university students from abroad and local students who may likewise leave home for study but within their own country. Finally, the study tested the efficacy of the five-stage well-being away model in terms of the pre-departure and being in university strategies employed by study away from home students and QUL. A large sample of away from home international and domestic university students completed a survey to measure multiple facets of their well-being, course load, support, and the extent to which they employed pre-departure and being in university strategies to mitigate their adjustment to away from home study. The results of the study contribute several findings that contribute to the literature on the well-being of away from home university students.

\subsection{Between Group Differences}

There were several differences between international and domestic students on positive personality, course demands, satisfaction with university facilities and negative wellbeing. International students also reported higher employment of pre-departure strategies, the reason for that is likely because the decision of studying overseas required a long process and students may spend months starting with discussing the idea with family or close friend, choosing an institution until getting their visa. An explanation of why British students reported higher levels of course demand and negative well-being than international students is due to either financial issues or stressors from working either full or part-time. According to the National Union of Students Report (2008), $35 \%$ of students worked part-time during term time to support themselves at university, and previous research has shown a significant relationship between financial problems and mental health among British students (Andrews \& Wilding, 2004; Roberts, Golding, Towell, \& Weinreb 1999). To test this possibility, future research may include questions about either working hours or financial difficulties or issues faced by university students.

In terms of demographic factors, female students in the current study reported significantly lower levels of positive personality. Conversely, they also reported higher levels of negative wellbeing and course demand 
compared to male students. This finding was consistent with previous research by Stallman (2010) with Australian university students, where being female was a predictor of mental health problems or distress. The findings also showed that non-first year students reported lower scores for quality of university life and were less satisfied with university facilities. This finding was consistent with a longitudinal study by Bewick, Koutsopoulou, Miles, Slaa, and Barkham (2010) who found anxiety scores amongst UK university students peaked in the first term of both the second and final years. It is likely that students in later years of study are experiencing more pressure, whereas first year students are perhaps in a 'honeymoon phase' of being at university. Non-first year students also reported lower scores for healthy lifestyle that may be linked with being stressed or depressed in their university life. When comparing between first-year and non-first year students our results are consistent with other those obtained in other studies. However, it should be noted that participants were only asked if they were in their first year or other years. In future research, it is important to examine related factors such as the length of stay for certain students, particularly international students, in their first year. This is because some international students before starting their course are expected to do language courses such as pre-sessional course in the host country, and factors such as experience of being aboard before and age might also have an effect on their well-being.

\subsection{Predictors of Student Well-Being}

Regression analysis showed several variables predicted positive well-being, the findings showed students with a healthy lifestyle and a positive personality reported higher positive well-being and students with higher control and support, quality of university life and being away strategies reported higher positive well-being. Consistent with this finding, students with a less healthy lifestyle and less positive personality reported higher negative well-being and those with lower control and support showed higher negative well-being. As such, the predictors of student well-being reported in this study are consistent with several lines of research in wellbeing. For example, Burris, Brechting, Salsman and Carlson (2009) reported that optimism was the best predictor of both psychological wellbeing and lower levels of psychological distress; being healthy was positively associated with psychological well-being amongst US university students. Importantly, for studying away, other factors such as attitude to studying abroad or student motivation to study away or abroad might have a large effect on well-being. Moreover, positive personality might mediate or moderate the relation between these factors and well-being, so further studies focusing on these variables need to be conducted. The findings are also aligned with the research by Cho and $\mathrm{Yu}$ (2015) which showed that university support has a positive effect on international students' wellbeing and school satisfaction.

Regression analysis further showed that being away strategies were predictive of positive wellbeing. This finding indicates that students who did not depend on technology and who participated in different activities after work had a higher level of wellbeing, which implies the important role of campus/union entertainment facilities to support students. The findings also showed the employment of pre-departure strategies did not directly predict any well-being outcomes either positively or negatively. This may be due to the possibility that students could contact their family and friends most of the time via technology and social media apps. Research has found that young adults' dependence on social media for social connections has increased not only in the US but around the world (Duggan et al., 2015; Fox \& Rainie, 2014; International World Stats, 2015). This strategy may have direct effect on wellbeing when it applies to people who either have limited time to use social media or lack access to the Internet.

Although there was no direct effect of pre-departure strategies on student well-being, there was a significant interaction between nationality and pre-departure strategies on negative well-being. Regression analysis showed international students who employed fewer pre-departure strategies showed higher negative well-being. This is an important finding and provides some support to the Sodexo (2014) away from home well-being model which proposed that the employment of pre-departure strategies help an individual sojourner to maintain and manage their own level of well-being and makes the adjustment process easier and with fewer negative outcomes.

One important finding from this study was that the QUL was predicted by applying being away strategies - during pre-departure and while at university - as well as other positive elements, which means that students who used those strategies found their university life better than students who did not. Consistent with other research (Sirgy et al. 2010; Yu and Lee 2008), QCL / QUL has a crucial role in positive well-being. Unfortunately, our study did not include academic achievement, although in recent meta-analysis done by Bucker, Nuraydin, Simonsmeier, Schneider and Luhmann (2018), it was shown that low achievement does not necessarily result in negative well-being and high achievement does not automatically mean better quality of life. However, it is worth considering whether students who study away from home and whether their wellbeing strategies and/or QUL have an impact on academic achievement as well as an association with positive and 
negative wellbeing.

\section{Limitations and Future Research}

Although the results from this study provide some noteworthy findings on the factors that impact on the well-being of away from home university, there are several limitations that limit the generalizability of the findings. In terms of the sample of participants, the home student sample came from only one university, which means that we cannot generalise the findings to all home students. Additionally, self-selection bias is another potential limitation of the online survey employed to conduct the current research (Wright, 2005). Despite these issues, the study used a reasonable sample size for the study, which broadly represented away from home international and domestic university students in terms of gender, age, and year of university study.

A further limitation of the findings is that the correlational nature of the research design does not produce information about definitive cause-effect relationships between healthy lifestyle, positive personality, pre-departure strategies and being in university strategies and well-being. Nevertheless, the correlational method provided several practical and pragmatic benefits in this study, including the capacity to investigate a range of concepts related to away from home student well-being intentions simultaneously. As shown by the high reliabilities of the measures of employed in this study, the online questionnaire format provided a relatively valid and efficient means of data collection.

The findings of the study also point to several directions for future research. Although the impact of pre-departure strategies on away from home student well-being was limited, there was some evidence to support future research to investigate the efficacy of the Sodexo (2014) model. Future research may employ more measures of each of the 5-phases of away from home well-being model with longitudinal studies to track the well-being of students from pre-departure to being back home. The findings also suggest that future research might compare international and home students who study away from their home and investigate the role of additional factors that may impact on the well-being of away from home students such as financial issues, coping strategies and social support from different providers like family, university services and/or staff. Finally, future research with qualitative research methods such as semi-structured interviews would provide an in-depth understanding of the subjective experience of university students who leave home to pursue higher education qualifications.

\section{Summary and Conclusion}

The objective of the current study was to contribute to knowledge about factors that are likely to impact on the well-being of students who leave home to pursue higher education qualifications. A survey study was conducted with British and international students who leave home to attend university in the UK and they provided information about their experience of support, course demands, well-being, and pre-departure and at university strategies they used to manage the transition to university life and study. The findings showed that international students reported higher levels of positive personality and experienced better QUL. They also found their courses less demanding than British students and used more pre-departure strategies than home students. Regression analysis also showed international students who employed more pre-departure strategies showed lower negative well-being and use of these strategies was a significant predictor of positive wellbeing and quality of university life. From the findings, it may be concluded that the employment of pre-departure strategies is likely to help an individual sojourner maintain and manage their own level of well-being and makes the adjustment process easier and with fewer negative outcomes.

\section{References}

Alharbi, E. S., \& Smith, A. P. (2018). A review of the literature on stress and wellbeing among international students in English-speaking countries. International Education Studies, 11(6), 22-44. https://doi.org/10.5539/ies.v11n6p22

Andrade, M. S. (2006). International students in English-speaking universities. Journal of Research in International Education, 5, 131-154. https://doi.org/10.1177/1475240906065589

Andrews, B., \& Wilding, J. (2004). The relation of depression and anxiety to life-stress and achievement in students. British Journal of Psychology, 95, 509-521. https://doi.org/10.1348/0007126042369802

Bewick B., Koutsopoulou G., Miles J., Slaa E., \& Barkham, M. (2010). Changes in undergraduate students' psychological wellbeing as they progress through university. Studies in Higher Education, 35, 633-645. https://doi.org/10.1080/03075070903216643

Bücker, S., Nuraydin, S., Simonsmeier, B. A., Schneider, M., \& Luhmann, M. (2018). Subjective Well-Being and 
Academic Achievement: A Meta-Analysis. Journal of Research in Personality, 74, 83-94. https://doi.org/10.1016/j.jrp.2018.02.007

Burris, J. L., Brechting, E. H., Salsman, J., \& Carlson, C. R. (2009) Factors associated with the psychological wellbeing and distress of university students. Journal of American College Health, 57(5), 536-544. https://doi.org/10.3200/jach.57.5.536-544

Chen, C. P. (1999). Professional Issues: Common stressors among international college students: Research and counseling implications. Journal of College Counseling, 2, 49-65. https://doi.org/10.1002/j.2161-1882.1999.tb00142.x

Constantine, M. G., Okazaki, S., \& Utsey, S. O. (2004). Self-concealment, social self-efficacy, acculturative stress, and depression in African, Asian, and Latin American international college students. The American Journal of Orthopsychiatry, 74(3), 230-241. https://doi.org/10.1037/0002-9432.74.3.230

Cotton, S. J., Dollard, M. F., \& de Jonge, J. (2002) Stress and student job design: satisfaction, wellbeing, and performance in university students. International Journal of Stress Management, 9(3), 147-162. https://doi.org/10.1023/A:1015515714410

Fisher, S., \& Hood, B. (1987). The stress of the transition to university: A longitudinal study of psychological disturbance, absent-mindedness and vulnerability to homesickness. British Journal of Psychology, 78, 425-441. https://doi.org/10.1111/j.2044-8295.1987.tb02260.x

Fisher, S., Frazer, N., \& Murray, K. (1984). The transition from home to boarding school: A diary style analysis of the problems and worries of boarding school pupils. Journal of Environmental Psychology, 4, 211-221. https://doi.org/10.1016/S0272-4944(84)80042-0

Gardner, B., Alfrey, K-L., Vandelanotte, C., \& Rebar, A. L. (2018). Mental health and well-being concerns of fly-in fly-out workers and their partners in Australia: a qualitative study. BMJ Open, 8(3), e019516. https://doi.org/10.1136/bmjopen-2017-019516

Gilliver, S. C., Sundquist, J., Li, X., \& Sundquist, K. (2014). Recent research on the mental health of immigrants to Sweden: a literature review. European Journal of Public Health, 24(Suppl 1), 72-79. https://doi.org/10.1093/eurpub/cku101

Hamamura, T., \& Laird, P. G. (2014). The effect of perfectionism and acculturative stress on levels of depression experienced by East Asian international students. Journal of Multicultural Counseling and Development, 42, 205-217. https://doi.org/10.1002/j.2161-1912.2014.00055.x

Hechanova-Alampay, R., Beehr, T. A., Christiansen, N. D., \& Van Horn, R. K. (2002). Adjustment and Strain among Domestic and International Student Sojourners: A Longitudinal Study. School Psychology International, 23(4), 458-474. https://doi.org/10.1177/0143034302234007

Howell, D. C. (2002). Statistical methods for psychology. Pacific Grove, CA: Thomson Learning.

Kealy, D. J. (1989). A study of cross-cultural effectiveness: Theoretical issues, practical applications. International Journal of Intercultural $\quad$ Relations, $13, \quad 387-428$. https://doi.org/10.1016/0147-1767(89)90019-9

Keyes, C. L. M. (2005). Mental health and/or mental illness? Investigating axioms of the complete state model of health. Journal of Consulting and Clinical Psychology, 73, 539-548. https://doi.org/10.1037/0022-006X.73.3.539

Khawaja, N. G., \& Dempsey, J. (2008). A comparison of international and domestic tertiary students in Australia. Australian Journal of Guidance and Counselling, 18(1), 30-46. https://doi.org/10.1375/ajgc.18.1.30

Martin, J. N., Bradford, L., \& Rohrlich, B. (1995). Comparing predeparture expectations and post-sojourn reports: A longitudinal study of U.S. students abroad. International Journal of Intercultural Relations, 19(1), 87-110. https://doi.org/10.1016/0147-1767(94)00026-T

Moore, J. (2000). Placing home in context. Journal of Environmental Psychology, 20(3), $207-217$. https://doi.org/10.1006/jevp.2000.0178

Mori, S. (2000). Addressing the mental health concerns of international students. Journal of Counseling \& Development, 78, 137-144. https://doi.org/10.1002/j.1556-6676.2000.tb02571.x

Mortenson, S. T. (2006). Cultural differences and similarities in seeking social support as a response to academic failure: A comparison of American and Chinese college students. Communication Education, 55(2), 
127-146. https://doi.org/10.1080/03634520600565811

Pitkethly, A., \& Prosser, M. (2010) The First Year Experience Project: A model for university-wide change. Higher Education Research \& Development, 20(2), 185-198. https://doi.org/10.1080/758483470

Rahat, E., \& Ilhan, T. (2016). Coping styles, social support, relational self-construal, and resilience in predicting students' adjustment to university life. Educational Sciences: Theory and Practice, 16(1), 187-208. https://doi.org/10.12738/estp.2016.1.0058

Roberts, R., Golding, J., Towell, T., \& Weinreb, I. (1999). The effects of economic circumstances on British students' mental and physical Health. Journal of American College Health 48, 103-109. https://doi.org/10.1080/07448489909595681

Rosenthal, D. A., Russell, J., \& Thomson, G. (2008). The health and wellbeing of international students at an Australian university. Higher Education, 55(1), 51-67. https://doi.org/10.1007/s10734-006-9037-1

Sanders, A. E., \& Lushington, K. (1999). Sources of stress for Australian dental students. Journal of Dental Education, 63, 688-697.

Sandhu, D. S., \& Asrabadi, B. R. (1994). Development of an acculturative stress scale for international students: Preliminary findings. Psychological reports, 75(1), 435-448. https://doi.org/10.2466/pr0.1994.75.1.435

Simmala, B. (2008). Cross-cultural adjustment of Asian international graduate students in the United States: Theorizing from the literature. Adult Education Research Conference. Retrieved from https://newprairiepress.org/aerc/2008/papers/64

Sirgy, M. J., Grzeskowiak, S., \& Rahtz, D. (2007). Quality of college life (QCL) of students: Developing and validating a measure. Social Indicators Research, 80, 343-360. https://doi.org/10.1007/s11205-005-5921-9

Sirgy, M. J., Lee, D. J., Grzeskowiak, S., Yu, G. B., Webb, D., El Hasan, K., .. Kuruuzum, A. (2010). Quality of college life (QCL) of students: Further validation of a measure of well-being. Social Indicators Research, 99(3), 375-390. https://doi.org/10.1007/s11205-010-9587-6

Smith, A. P., Smith, H. N., \& Jelley, T. (2018). Studying Away Strategies: Well-being and Quality of University Life of International Students in the UK. Journal of Education, Society and Behavioral Science, 26(4), 1-14. https://doi.org/10.9734/jesbs/2018/43377

Sodexo. (2014). Well-being away Report. Retrieved from https://www.qualityoflifeobserver.com/sites/default/ files/wellbeing-away-report_sodexo-insititute-quality-of-life.pdf

Stallman, H. M. (2010). Psychological distress in university students: A comparison with general population data. Australian Psychologist, 45, 249-257. https://doi.org/10.1080/00050067.2010.482109

UKCISA. (2016-17). International student statistics: UK higher education. https://doi.org/10.1007/978-3-319-51073-6_3

UNITE. (2016). Students resilience: Unite Students Insight Report. Retrieved from https://www.unitestudents.com/about-us/insightreport

Ward, C., \& Kennedy, A. (2001). Coping with Cross-Cultural Transition. Journal of Cross-Cultural Psychology, 32, 636-642. https://doi.org/10.1177/0022022101032005007

Wright, K. B. (2005). Researching Internet-based populations: Advantages and disadvantages of online survey research, online questionnaire authoring software packages, and web survey services. Journal of Computer Mediated Communication, 10(3). https://doi.org/10.1111/jcmc.2005.10.issue-3

Yu, G. B., \& Kim, J.-H. (2008). Testing the mediating effect of the quality of college life in the student satisfaction and student loyalty relationship. Applied Research in Quality of Life, 3(1), 1-21. https://doi.org/10.1007/s11482-008-9044-8

Yu, G., \& Lee, D.-J. (2008). A model of quality of college life (QCL) of students in Korea. Social Indicators Research, 87(2), 269-285. https://doi.org/10.1007/s11205-007-9172-9 


\section{Appendix}

\section{Smith Student Well-being Questionnaire (SWELL)}

$$
(1=\text { Not at all, } 10=\text { very much so })
$$

Q1. A healthy lifestyle involves taking exercise, eating a balanced diet, not smoking, not drinking excessive amounts of alcohol, and not being overweight. To what extent do you have a healthy life style?

\section{0}

Q2. People often describe themselves as being positive ("seeing the glass as half full") or negative ("seeing the glass as half empty"). How would you describe yourself?

$$
12345678910
$$

\section{Please answer the next set of questions by "Thinking about the last 6 months":}

Q3. How satisfied are you with life in general?

$$
12345678910
$$

Q4. How much stress have you had in your life in general?

$$
12345678910
$$

Q5. Would you say you are generally happy?

$$
12345678910
$$

Q6. Would you say that you generally feel anxious or depressed?

$$
12345678910
$$

Q7. Overall, to what extent do you feel the things you do in your life are worthwhile?

$$
12345678910
$$

Q8. How demanding do you find your course (e.g. do you have constant pressure, have to work fast, have to put in great effort)?

$$
12345678910
$$

Q9. Do you feel you have control over your academic work and support from staff and fellow students?

$$
12345678910
$$

Q10. How much stress do you have because of your university work?

$$
12345678910
$$

Q11. Are you satisfied with your course?

$$
12345678910
$$

Q12. How physically or mentally tired do you get because of your academic work?

$$
12345678910
$$

Q13. Have you had an illness (either physical or mental) caused or made worse by your academic work?

$$
\begin{array}{ll}
\text { O Yes } \\
\text { O No }
\end{array}
$$

Q14. Do you ever come to University when you are feeling ill and knowing you can't work as well as you would like to?

O Yes

O No

Q15. How efficiently do you carry out your academic work?

$$
12345678910
$$

Q16. Do you find your academic work interferes with your life outside of university or your life outside of university interferes with your course?

$$
12345678910
$$


Q17. Are you happy at university?

$$
12345678910
$$

Q18. Are you anxious or depressed because of academic work?

12345678910

\section{Quality of University Life Questionnaire}

Q1. To what extent do you feel that your university life is easy and efficient?

$$
12345678910
$$

Q2. To what extent do you feel that being a student at university promotes a healthy lifestyle through well-balanced diet and exercise?

$$
12345678910
$$

Q3. To what extent do you feel you are valued at the university?

$$
12345678910
$$

Q4. To what extent does the university provide a good physical environment?

$$
12345678910
$$

Q5. To what extent does the university strengthen bonds among individuals and facilitate access to culture and entertainment?

$$
12345678910
$$

Q6. To what extent does the university promote learning and progress?

$$
12345678910
$$

\section{Being Away Strategies Questionnaire}

Before you left home: Q1. To what extent did you carry out pre-departure planning with family or friends?

$$
12345678910
$$

Q2. To what extent did you discuss expectations of how being apart will feel?

$$
12345678910
$$

Q3. To what extent did you say "goodbye" properly and in a way that acknowledges the reality of the coming separation?

$$
12345678910
$$

Q4. To what extent did you agree on likely communications while away?

$$
12345678910
$$

Being at university: Q5. To what extent have you acknowledged and adapted to being away?

$$
12345678910
$$

Q6. To what extent do you live the reality of being away without over-reliance on technology (your phone, e-mail, Skype or social media)?

$$
12345678910
$$

Q7. To what extent do you make an effort to unwind after academic work?

$$
12345678910
$$

\section{Copyrights}

Copyright for this article is retained by the author(s), with first publication rights granted to the journal.

This is an open-access article distributed under the terms and conditions of the Creative Commons Attribution license (http://creativecommons.org/licenses/by/4.0/). 